\title{
A molecular perspective: biology of the emerging pathogen Batrachochytrium dendrobatidis
}

\author{
Erica Bree Rosenblum ${ }^{1, *}$, Matthew C. Fisher ${ }^{2}$, Timothy Y. James ${ }^{3}$, \\ Jason E. Stajich ${ }^{4,6}$, Joyce E. Longcore ${ }^{5}$, Lydia R. Gentry ${ }^{1}$, Thomas J. Poorten ${ }^{1}$ \\ ${ }^{1}$ Department of Biological Sciences, University of Idaho, Moscow, Idaho 83844, USA \\ ${ }^{2}$ Department of Infectious Disease Epidemiology, Imperial College, London W2 1PG, UK \\ ${ }^{3}$ Department of Ecology and Evolutionary Biology, University of Michigan, Ann Arbor, Michigan 48109, USA \\ ${ }^{4}$ Department of Plant and Microbial Biology, University of California, Berkeley, California 94720, USA \\ ${ }^{5}$ Department of Biological Sciences, University of Maine, Orono, Maine 04469, USA \\ ${ }^{6}$ Present address: Department of Plant Pathology and Microbiology, University of California, Riverside, \\ California 92521, USA
}

\begin{abstract}
Ten years after the first discovery of the chytrid pathogen Batrachochytrium dendrobatidis $(B d)$, the catastrophic effect of $B d$ on wild amphibian populations is indisputable. However, a number of persistent questions remain about $B d$ 's origin and mechanisms of pathogenicity. Here we discuss the promise of genetic and genomic tools for answering these previously intractable questions about the biology and evolutionary history of $B d$. Full genomes of $2 B d$ strains have recently been sequenced, and $B d$ research on this species using population genetics, phylogenetics, proteomics, comparative genomics and functional genomics is already underway. We review some of the insights gleaned from the first studies using these genome-scale approaches focusing particularly on $B d$ 's genomic architecture, patterns of global genetic variation, virulence factors and genetic interactions with hosts. Avenues of future research promise to be particularly fruitful and highlight the need for integrative studies that unite genetic, ecological and spatial data in both $B d$ and its amphibian hosts.
\end{abstract}

KEY WORDS: Genetics · Genomics · Ecological genomics ' Pathogenicity · Chytrid · Batrachochytrium dendrobatidis

Resale or republication not permitted without written consent of the publisher

\section{INTRODUCTION}

Despite the wealth of information on the distribution and ecology of the amphibian disease chytridiomycosis, little is known about the basic biology of the disease agent Batrachochytrium dendrobatidis $(B d) . B d$ is enigmatic in part because it is the first known pathogen of vertebrates from an understudied phylum of Fungi, the Chytridiomycota. Chytridiomycota is among the earliest diverging lineages on the fungal tree of life. Unlike the 'higher' fungi the asexual spores of chytrids, termed zoospores, are motile and possess a single flagellum. Chytrids are ubiquitously distributed in aquatic ecosystems and soils as saprobes and para- sites. Although many chytrids specialize on refractory substrates like pollen and keratin, $B d$ is the first chytrid known to attack living vertebrates.

After almost a decade of study, some of the key questions regarding the evolution and genetics of $B d$ remain a mystery. Where and when did $B d$ emerge? Is the symbiosis between amphibians and $B d$ ancient or a recent host or habitat shift? What factors lead to observed global and local patterns of $B d$ spread? How does $B d$ persist outside the host? What is the precise mechanism by which $B d$ kills its hosts? Why do some frog species and populations persist after $B d$ introduction while others are decimated? What genes are involved in $B d$ pathogenicity? Is there a 
genetic basis to hypothesized strain differences in virulence?

The scientific effort targeted toward answering these questions in $B d$ has been steadily rising over the last decade (Fig. 1), but not surprisingly for a pathogen of wildlife, most publications are ecological in focus. Relatively few studies of $B d$ have used molecular approaches, and of these most employed molecular methods only for pathogen detection. PCR and realtime PCR assays were introduced in 2001 (Dastoor et al. 2001, Annis et al. 2004) and 2004 (Boyle et al. 2004), respectively, and these diagnostic methods have been adopted fairly widely. However, the use of genetic tools for understanding the evolutionary history of $B d$ has been surprisingly rare, with only a handful of representative publications available (e.g. Morehouse et al. 2003, Morgan et al. 2007, Rosenblum et al. 2008, Fisher et al. 2009a, James et al. 2009).

Challenges are inherent in developing and using genetic tools in non-model systems, particularly for species like $B d$ that are phylogenetically divergent from genetically well-characterized relatives. However, many of these obstacles have recently been overcome with the completion of 2 separate $B d$ wholegenome sequencing projects. The Joint Genome Institute and the Broad Institute have completed sequencing, assembly, and annotation for 2 strains of $B d$ (JAM81 isolated from Rana muscosa in California, USA, and JEL423 isolated from Phyllomedusa lemur in Panama, respectively). These data usher in a new era for $B d$ studies; researchers now will be able to use genome-enabled molecular tools to address a variety of persistent issues from understanding $B d$ 's origin and spread to identifying genetic mechanisms of pathogenicity.

Here we look at the development of a molecular toolkit for $B d$, discuss some of the first genetic and genomic studies and consider future avenues of research that will be made possible by newly developed genetic tools. We focus on insights garnered from population genetics, phylogenetics, proteomics and comparative and functional genomics. Our hope is to draw attention to the merits of genetic tools in understanding disease-related amphibian declines (Fig. 2).

\section{Bd GENOMIC ACHITECTURE}

Sequencing of fungal genomes has escalated in the past $10 \mathrm{yr}$, and nearly 100 complete genome sequences are available. Yet, few genomes of early diverging fungal lineages, including Chytridiomycota, have been sampled. Fungi are ancient and a rough molecular clock suggests their diversification began as early as 0.4 to 1.9 billion yr ago (Taylor \& Berbee 2006). Understanding the history of early diverging lineages is challenging because of an increase in phylogenetic noise to signal over time. However, the availability of the complete $B d$ genome will allow us to better understand the phylogenetic placement of $B d$, the genetic landscape in $B d$, and the evolutionary history of fungi.

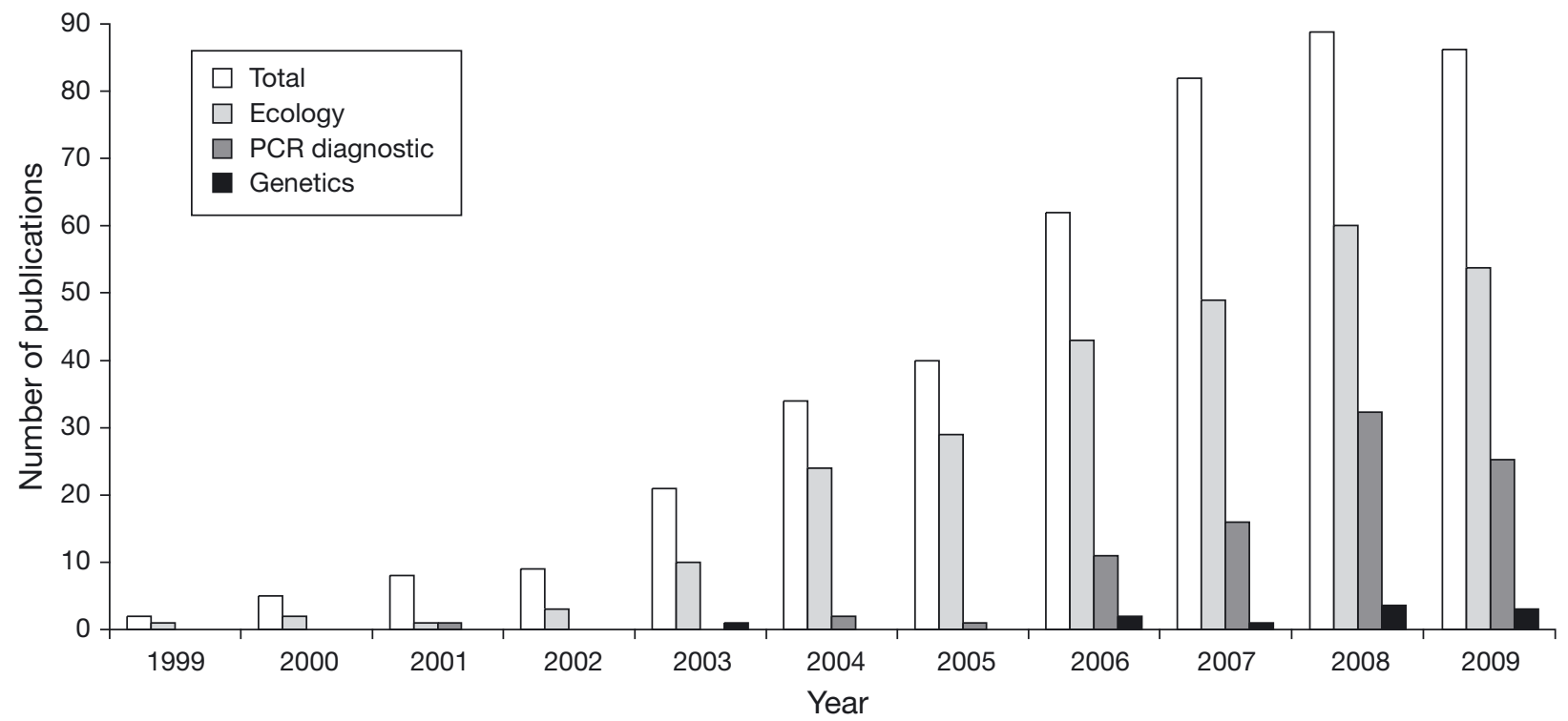

Fig. 1. Results of ISI Web of Knowledge keyword search for publications on Batrachochytrium dendrobatidis (Bd) from the initial species description (Longcore et al. 1999) through November 2009. Open bars represent total Bd publications ( $\mathrm{N}=437$ ), light grey bars represent ecologically focused publications $(\mathrm{N}=277)$, dark grey bars represent publications using PCR techniques for $B d$ detection ( $\mathrm{N}=88)$ and black bars represent publications using (non-PCR) genetic tools $(\mathrm{N}=9)$. Although this is not the inclusive set of all $B d$ papers, patterns are indicative of a paucity of genetic studies of this species 


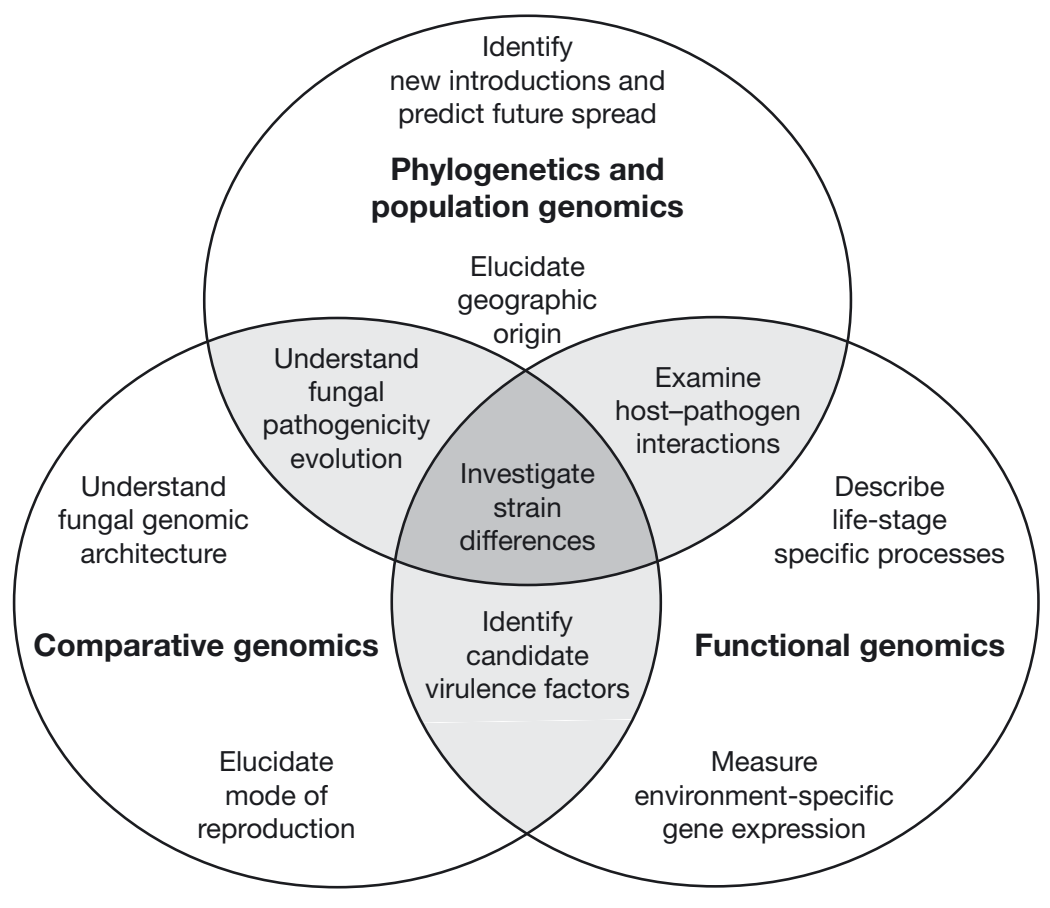

Fig. 2. Schematic of uses for the Batrachochytrium dendrobatidis $(B d)$ genome with representative topics that can be illuminated with genetic data. Topics shown are examples only; a wealth of research questions can be addressed using genetic and genomic approaches for $B d$ pure culture, suggesting that $B d$ is not unique in the Rhizophydiales in being able to develop within the cells of its host. Isolate 142 also differs from the majority of the Rhizophydiales in that instead of having a single rhizoidal axis, it has multiple axes. Unfortunately the phylogenetic distance between $B d$ and the strains most closely related to it is rather large, and numerous extant or extinct taxa have probably diverged along the branch uniting $B d$ and its most recent common ancestor. The complete genome sequence will provide a wealth of data useful for reconstructing the history of $B d$, including a complete inventory of gene sequences necessary to allow more precise phylogenetic placement. A robust phylogenetic hypothesis will also facilitate the use of comparative methods to better understand changes that have occurred along the branch leading to $B d$. Additional genomic data for $B d$, however, does not alleviate the need for more thorough sampling of species and genes from related chytrid taxa.

\section{Phylogenetic placement}

Systematics of the Chytridiomycota currently relies on ultrastructural characters of the zoospore combined with molecular characters, primarily of ribosomal DNA (e.g. Letcher et al. 2006, Simmons et al. 2009). Based on this approach, $B d$ is currently assigned to a group of primarily saprobic species, the Rhizophydiales (Letcher et al. 2006). Most members of the Rhizophydiales develop only endogenously (the nucleus remains in the zoospore cyst and the cyst expands to form the zoosporangium). However, $B d$ appears to develop endogenously when in pure culture and, presumably, exogenously (the nucleus leaves the zoospore cyst and is conveyed into the substrate by a germ tube) when growing in amphibian skin (Berger et al. 2005).

Molecular data recently have been employed to assess the phylogenetic position of $B d$ among the isolates of zoospore-producing fungi now in culture. Data from ribosomal DNA sequences (James et al. 2000, 2006) and protein-encoding DNA sequences (T. Y. James unpubl. data) suggest that $B d$ is most closely related to 3 saprophytic chytrid isolates (Entophlyctis helioformis [JEL122 and JEL326] and an unidentified isolate [JEL142]). E. helioformis develops exogenously in its natural substrates (algal or plant cells) and in

\section{Genome size and ploidy}

In general, Fungi have compact genomes, typically ranging between $\sim 8$ and $60 \mathrm{Mbp}$ (Zolan 1995), and lack some of the highly repetitive DNA and large introns found in vertebrate genomes. Fungal genomes, instead, tend to have genes with many introns, but these introns are shorter than those in animals and plants (Stajich et al. 2007). The percentage of fungal genomes composed of transposable elements ranges from extremely minimal $(0.35 \%$ in Schizosaccharomyces pombe) to relatively high in some Basidiomycetes (e.g. $21 \%$ in Laccaria bicolor, Curran \& Bugeja 2005, Martin \& Selosse 2008). Bd genes are intron rich, similar to Mucorales fungi such as Rhizopus oryzae, supporting the inference that the animalfungal ancestor had complex, intron-rich gene structure (Stajich et al. 2007, J. E. Stajich unpubl. data).

Most fungi are assumed to be vegetatively haploid with zygote formation and karyogamy followed immediately by meiosis. However, some species are vegetatively diploid (e.g. Armillaria gallica, Saccharomyces cerevisiae and Candida albicans, Ullrich \& Anderson 1978, Mortimer 2000, Noble \& Johnson 2007, respectively), and some members of the Blastocladiomycota have both haploid and diploid vegetative phases. Little 
is known about ploidy and mating genetics in Chytridiomycota, but the assumption has been that they are vegetatively haploid with zygotic meiosis (Doggett \& Porter 1996). However, genotyping studies in $B d$ have shown 2 alleles per locus (Morehouse et al. 2003, Morgan et al. 2007) suggesting that $B d$ is diploid. DNA sequencing of other members of the Chytridiomycota suggests that diploidy may be more prevalent than was previously appreciated in this group (Liu et al. 2006).

The earliest estimate of genome size in $B d$ was based on pulsed field gel electrophoresis of entire chromosomes. Each strain was estimated to have 14 to 20 chromosomes (Morehouse et al. 2003); a precise number could not be determined because of the difficulty in resolving large and similarly sized chromosomes by electrophoresis. Chromosomes varied in size from $\sim 0.7$ to 6.0 million base pairs $(\mathrm{Mb})$, and the genome size was estimated to be 35 to $40 \mathrm{Mb}$. Current assemblies of the 2 genomes of $B d$ reveal a haploid genome assembly size of $23.4 \mathrm{Mb}$ for strain JEL423 and $24.3 \mathrm{Mb}$ for the strain JAM81. Thus, the original estimate of genome size based on pulsed field gel electrophoresis appears to have been close to the estimated diploid size. Ultimately, the pulsed field gels and the genome assembly must be linked by hybridization of genes to separated chromosomes using techniques such as in situ hybridization of probes to chromosome preparations (fiber-FISH) or Southern blotting.

The difference in assembly sizes for the 2 sequenced strains suggest that some homologous chromosomes have different sizes, which is concordant with the identification of several chromosomal length polymorphisms between each of the $B d$ strains tested (Morehouse et al. 2003). Chromosomal length polymorphisms in $B d$ merit further study. It is tempting to speculate whether any genes important for pathogenesis can be found in these chromosomal regions that may be absent or duplicated in specific strains. A more precise estimate of chromosome number for each strain will also determine whether any strains are aneuploid (i.e. lack the full complement of pairs of homologous chromosomes). In other species, such as the human pathogen Candida albicans, aneuploidy of the mating-type chromosome has been linked to reduced virulence (Wu et al. 2007).

\section{Mode of reproduction}

The mating system of a species plays a crucial role in determining its evolutionary fate. Outcrossing promotes the mixing of allelic combinations between loci and generates high levels of genotypic diversity. In contrast, clonality, or asexual reproduction, allows the rapid amplification of genotypes that have been tested by natural selection without disrupting favorable epistatic interactions. Asexual reproduction also does not require locating a suitable mating partner.

Most fungi have the ability to reproduce asexually by the mitotic production of spores; however, a large portion can also reproduce sexually. One consistent result to emerge from genomic and population investigations in the last decade is that all fungal populations seem to undergo some form of recombination. Further, all fungal genomes have some genes that are involved in sex, even those of species that cannot be mated in the lab or do not exhibit any obvious signs of sex in nature (e.g. fruiting body). Furthermore, there is no convincing evidence of ancient asexual lineages in fungi (Taylor \& Berbee 2006).

The complete genome sequences for $B d$ will allow us to determine whether the fungus has the typical suite of mating-type genes and meiosis genes that have been observed in other fungi. Currently no identified mating-type locus has been described for a chytrid fungus, but recent work has identified the mating locus in the Zygomycete Phycomyces blakesleeanus through identification of high mobility group (HMG) domain genes and conserved gene order (Idnurm et al. 2008). Identification of mating and meiotic genes does not provide conclusive proof of actual sexual recombination because these genes' functions may include additional pleiotropic roles that prevent their loss by genetic drift. If genes for mating and meiosis are found in the $B d$ genome, then additional population genetic and morphological tests are required to identify whether mating does occur. These tests need to distinguish between meiotic and mitotic processes because genes can recombine in the absence of meiosis (Taylor et al. 1999).

Analyses of multiple microsatellite and single nucleotide polymorphism (SNP) markers support prevailing asexual reproduction in $B d$ (Morehouse et al. 2003, Morgan et al. 2007). Clonality is inferred because many of the loci show significant heterozygote excess inconsistent with Hardy-Weinberg equilibrium (HWE) expectations for sexual reproduction. However, the high level of genotypic diversity and the finding that some loci do show HWE proportions of genotypes creates a paradox. How is genotypic diversity created, and what is the recombination process that is occurring? A recent study of global diversity in $B d$ attempts to answer this question by surveying 17 polymorphic loci spread throughout the genome (James et al. 2009). The availability of the draft genome sequence of $B d$ allowed the assignment of these 17 loci to actual chromosome-sized fragments of DNA (supercontigs). These data showed that loci in HWE were not spread evenly throughout the genome; the largest supercontig appears to contain dispropor- 
tionately high numbers of loci in HWE. James et al. (2009) explained this phenomenon as the product of mitotic recombination acting to recombine smaller portions of the genome without the full reassortment expected from meiosis. Mitotic recombination can only effectively reduce heterozygosity, in a manner analogous to gene conversion or selfing; yet, like selfing, mitotic recombination has great potential to increase genotypic diversity and to facilitate the spread of beneficial mutations (Goodwin et al. 1994, Mandegar \& Otto 2007). A thorough test of the prevalence of mitotic recombination in the life history of $B d$ would be facilitated by learning the position of centromeres on supercontigs, because heterozygosity is predicted to be inversely correlated with distance to centromere under mitotic recombination (Mandegar \& Otto 2007). Genomic data can now be used to find centromeric regions using ab initio predictions that will allow us to test this model and identify whether the loss of heterozygosity occurs through mitotic recombination or meiotic processes.

Understanding reproduction in $B d$ reaches beyond the implications of recombination. The question of sexuality also bears on the possible production of a $B d$ resting spore, a resistant stage capable of enduring extreme conditions such as desiccation and heat. If a resting spore stage occurs in $B d$, it may have helped facilitate the intercontinental spread of the disease. In Chytridiomycota, sexual reproduction always leads to the production of a resting spore (although resting spores can also be asexually produced). No evidence of sexual reproduction or resting spore production has been observed in $B d$ to date, though a possible resistant stage has been reported in the Trasimeno Lake area in central Italy (Di Rosa et al. 2007). The occurrence of $B d$ in regions where seasonal temperatures fall above or below the survival range measured for $B d$ in the lab (Piotrowski et al. 2004) does not necessarily demonstrate a resting stage. Ambient temperatures can be quite different from microhabitat temperatures; however, these observations also illustrate the need for further exploration of the possibility of previously undescribed life-cycle stages.

\section{Fungal genomics}

The possibilities for using comparative genomics with the $B d$ genome are many and nested. At the finest scale, comparisons among the 2 sequenced $B d$ strains can help identify markers for study of population genetics as well as identify candidate genes associated with strain differences (see 'Global genetic variation' below). At a phylogenetically more inclusive scale, comparisons between $B d$ and non- $B d$ chytrid genomes will help determine what genetic changes have occurred along the branch to $B d$ and contribute to the unique biology of this species. Having genome sequences of additional chytrid fungi will therefore increase the utility of the $B d$ genome sequences. Efforts to sequence 2 additional zoospore-producing fungi are underway (Spizellomyces [Chytridiomycota] and Allomyces [Blastocladiomycota], Ruiz-Trillo et al. 2007). Spizellomyces, although in a different order (Spizellomycetales), will be the closest related fungus to $B d$ to have a genome sequence; comparisons at this level may help in understanding the $B d$ genome.

At the broadest scale, the $B d$ genome can teach us about the evolutionary history of basal fungi and allow us to infer characteristics of the common ancestor of all fungi. Despite being an early diverging lineage of fungi, chytrids share many of the features of more derived fungi such as cell wall structure, indeterminant growth (some species), carbon storage molecules, mitochondrial morphology and genome structure. Thus, comparative genomics can help us to understand the evolution of these fungal traits as well as other developmental and physiological traits that unite the group. For example, cell walls of all fungi contain chitin, but how diverse were the biosynthetic enzymes for construction of cell walls in the ancestral fungus? Interestingly, analysis of the $B d$ genome has shown the lack of the gene that codes for the enzyme $\beta(1,3)$ glucan synthase; this enzyme manufactures a key component of the cell walls of fungi, $\beta(1,3)$ glucan. Analysis of the mode of action of the $\beta(1,3)$ glucan synthase inhibitor, $B d$ is highly resistant to the anti-fungal drug, caspofungin, which suggests that the cell-wall of $B d$ is radically different to that of higher fungi (Fisher et al. 2009a). Finally, genome sequences from early branches in the fungal phylogeny will also provide insight about the (opisthokont) ancestor of fungi and animals. Some characteristics of chytrid fungi, such as the presence of a flagellated cell type, are shared with the sister metazoan clade and the $B d$ genome is already being used to make comparisons with genes in other eukaryotic clades (e.g. Parker et al. 2007).

\section{GLOBAL GENETIC VARIATION}

$B d$ promises to be an important and compelling model for understanding emergent and rapidly spreading pathogens. Genetic data can provide new insight into the evolutionary history of $B d$ at multiple spatial scales. In the following sections we discuss insights gleaned from molecular data on the origin and spread of $B d$, the distribution of global variation in this pathogen, and local patterns of $B d$ introduction. 


\section{Patterns of global spread}

Understanding the origin and spread of $B d$ is of crucial importance and is reviewed in detail elsewhere in this issue. Here we present a brief summary of competing hypotheses and highlight the contribution of genetic data to understanding the recent evolutionary history of $B d$. Two hypotheses compete to account for the emergent nature of chytridiomycosis. The first is the 'novel pathogen hypothesis' (NPH), based on a model of invasive spread into new geographic regions and host species. The second, the 'endemic pathogen hypothesis' (EPH), describes the emergence of chytridiomycosis as a consequence of an altered relationship between $B d$ and its amphibian hosts due to environmental change (reviewed by Rachowicz et al. 2005, Fisher \& Garner 2007). The ability to distinguish between the NPH and EPH is key to our understanding of the emergence of chytridiomycosis and developing appropriate conservation strategies.

The balance of ecological and spatiotemporal evidence to date shows that the NPH better describes the emergent epidemiology of $B d$ and chytridiomycosis; however, molecular tools are likely to provide the core evidence that will allow us to resolve the NPH verses the EPH debate. Importantly, we can generate expectations for the NPH that can be tested with molecular data. First, the earliest record of $B d$ is from 1938 in South Africa from Xenopus laevis, a species that could serve as a vector through the Xenopus trade (Weldon et al. 2004). If $B d$ spread from a center of emergence in South Africa, we would expect that the center of genetic diversity for $B d$ to be in South Africa, both at the individual and population levels. Second, population-genetic models derived from the expected distributions of genotypes resulting from different dispersal models can be tested by comparison with spatially sampled genotypes. For instance, the genetics of a global population that is derived from an early longdistance dispersal (LDD; leptokurtic or 'fat-tailed') event out of South Africa will be recognizably different from the genetics of populations that are in demographic equilibrium (expected under the EPH). Third, we expect that for frequent international dispersal expected under a NPH model of emergence identical multilocus genotypes (or highly related genotypes) will occur independently of geographical distance, and that $B d$ dispersal will be correlated with known movements of vectors.

Although existing genetic data do not fully resolve the mechanism of $B d$ origin and spread, several studies provide data that are more consistent with the NPH. In the first survey of genetic diversity in $B d$, Morehouse et al. (2003) sampled 10 regions of the genome by multilocus sequence typing for 35 isolates from 3 continents.
The rate of nucleotide polymorphism was extraordinarily low compared with that in most other fungi and microbes. Only 4 loci were polymorphic, and for each locus only 2 closely related alleles were found among all of the samples. The 35 isolates could not be grouped according to geography or host and some genotypes were widely distributed; isolates from Panama and Australia were completely identical in sequence over $5918 \mathrm{bp}$. These data provided some support for the NPH over the EPH because low levels of genetic diversity and widespread dispersal of identical genotypes are consistent with a recent bottleneck or range expansion. The study was limited, however, by the lack of diversity in sampled molecular markers, which prevented robust analysis of geographic patterns of genetic diversity and the reconstruction of statistically supported relationships among the samples. Although no particular geographic region had greater genetic diversity (suggestive of a source population), strong phylogeographic inference was impossible because of the extremely low diversity.

Across a finer spatial scale, Morgan et al. (2007) sampled nearly 100 isolates of $B d$ from 6 populations of the mountain yellow-legged frog complex Rana muscosa and $R$. sierrae from the Sierra Nevada Mountains, California. These populations of amphibians have been suffering from epidemic chytridiomycosis, which has caused steep population declines (Rachowicz et al. 2006). The study also included $7 B d$ isolates that were acquired from regions other than the Sierra Nevada Mountains, including South Africa and Australia. Multilocus genotypes were ascertained for 15 polymorphic loci, resulting in the discrimination of 24 multilocus genotypes. In the resulting genotype network, isolates from the Sierra Nevada Mountains divided roughly into northern and southern clades. That these Sierran $B d$ clades were equally closely related to 'international' $B d$ isolates as they were to each other is evidence against geographical endemism, and is consistent either with introductions of $B d$ into the Sierra Nevada Mountains at 2 different geographical foci or in situ divergence of $B d$ isolates within this mountain range.

A study of $B d$ prevalence and genetic diversity has recently been reported from Japan (Goka et al. 2009). Over 2600 swabbed amphibians were tested for $B d$ infection using diagnostic PCR of the internal transcribed spacer (ITS) ribosomal RNA region, and positively infected animals were subjected to DNA sequencing. These data suggested that captive and introduced populations of the North American bullfrog Rana catesbeiana had a high infection incidence and possessed the greatest haplotype diversity among hosts. Another species with an apparently high rate of infection incidence, the giant Japanese salamander Andrias japoni- 
cus, was infected by $B d$ genotypes that were only recovered from this host. Because only a single marker locus of uncertain copy number was used in this study, these intriguing results suggesting host-specificity of $B d$ genotypes must be viewed as preliminary until further confirmation with additional genetic data.

In a recent study of $59 \mathrm{Bd}$ isolates from 5 continents, James et al. (2009) generated data for the combined variable markers of Morehouse et al. (2003) and Morgan et al. (2007). Again, only 2 alleles were found at each of 17 loci despite the increased sampling of isolates. The study included over 30 host species including isolates from Xenopus and North American bullfrogs. Isolates from temperate North America and Europe had a higher overall genetic diversity than did the limited number of isolates from tropical America, Australia and Africa. The presence at 3 of the 17 loci of alleles unique to North America and Europe suggested recent gene flow between these 2 regions. Diversity was higher in bullfrogs than Xenopus, 2 hypothesized vectors of $B d$, but again, limited sampling of frogs prevented robust statistical testing of hypotheses related to origin of the disease. Nonetheless, the data strongly supported the NPH because the entire global diversity could be explained by the widespread distribution of a single diploid individual followed by diversification through mitotic recombination, a process with a similar outcome as self-fertilization.

Together, these studies provide persuasive evidence that there has been global dispersal of $B d$. Genetic data also suggest that the global populations of $B d$ probably descended from a small population of genetically 'bottlenecked' ancestors; rarely more than 2 alleles are found at a locus, and the majority of sequences are not polymorphic (Morehouse et al. 2003, Morgan et al. 2007, James et al. 2009). Direct evidence of bottleneck events is also evident from recent single-strain introductions to previously $B d$-free localities (see 'New introductions' section, Walker et al. 2007). Additional work is necessary, however, to understand local versus global patterns of $B d$ genetic diversity. For example, Morgan et al. (2007) observed a high degree of relatedness between genotypes within compared with between sites in the Sierra Nevada Mountains. Furthermore, no genotypes were shared between sites, and most genotypes could be assigned to their correct population with a significance of over $95 \%$. This suggests that $B d$ may be undergoing local genetic diversification within the Sierra Nevada Mountains. A similar process of host specialization may be occurring in Japan on the giant salamander host Andrias japonicus (Goka et al. 2009). What is uncertain is the time scale over which such differentiation can occur.

The seeming paradox between local and global patterns of diversity can be resolved by addressing sev- eral important questions with additional data. How is it that similar levels of genetic variation can be observed for $B d$ at the local and global scales? How do we reconcile a model of rapid global spread with the time necessary for $B d$ to become spatially structured at a local scale? How quickly can genetic differentiation occur for $B d$ under different demographic scenarios? To answer these questions we need additional studies at nested spatial scales. Studies of genetic variation at local and regional scales will help us understand whether patterns of genetic variation in the Sierra Nevada Mountains and Japan are similar to other regions. Studies at a global scale will be useful to identify the original source population (or populations) and the mechanisms that may be important in vectoring $B d$. More highly variable markers are needed for future studies; these markers can now be developed by comparisons between the sequenced strains (see 'New marker development' section below).

\section{New introductions}

In addition to understanding global patterns of spread, molecular markers can also be used to identify new introductions. For example, it has been argued that understanding the global trade in amphibians is key to identifying the major routes of spread of $B d$, and indeed it is likely that many of the over 26000000 individual living amphibians that entered the USA legally during 2000 to 2004 (Jenkins et al. 2007) were infected (Fisher \& Garner 2007, Picco \& Collins 2008). That Morgan et al. (2007) found that the northern and southern $B d$ clades overlap in the central Sierra Nevada Mountains, and at sites that are associated with high levels of human movement, is suggestive of a recent anthropogenic spread within the Sierra Nevada mountain range. However, direct evidence of human-mediated movement of $B d$ has, until recently, been lacking. Surveillance data also show that $B d$ has probably been introduced recently in Dominica (Garcia et al. 2007), the UK (Cunningham et al. 2005), New Zealand (Bell et al. 2004), Hawaii (Beard \& O'Neill 2005), Japan (Une et al. 2008), Sardinia (Bovero et al. 2008) and Mallorca (Walker et al. 2008).

The introduction of $B d$ to Mallorca is a particularly interesting case study. The finding in 2004 of a dead individual of a Mallorcan midwife toad Alytes muletensis in its native habitat, and the subsequent confirmation of its death from chytridiomycosis, raised the spectre of disease introduction into 1 of the 100 most globally endangered amphibian species. Surveillance of the island's breeding sites using PCR showed that the majority of infected individuals were clustered in 2 adjacent sites, one of which had a history of intro- 
duction of A. muletensis from a zoo captive-breeding program. Isolation and genotyping of $B d$ from the infected sites showed that isolates were genetically identical. Phylogenetic comparison against a global database of isolates showed that the isolates were unrelated to those that had been recovered from mainland Spain or the UK. Subsequent examination of zoo breeding records showed that captive A. muletensis had unusual mortality in 1989 when animals were cohoused with Xenopus gilli from South Africa; formalinpreserved corpses of both species were determined to be $B d$-positive by quantitative PCR and histology. These data are consistent with the hypothesis that cross-contamination of Mallorcan midwife toads by Xenopus, followed by introduction of the infected animals to Mallorca, vectored $B d$ onto the island. However, significant relatedness between the Mallorcan $B d$ genotypes and other isolates from South Africa was not observed, suggesting that either sampling of $B d$ genetic diversity in South Africa is incomplete, or that both species were infected from a third, as yet unidentified, source.

\section{Strain differences}

Despite the apparent rapid and global spread of $B d$, evidence is accumulating that isolates differ significantly in measurable biological traits that may have an effect on virulence. The first observation of differences between isolates in their biological characteristics were by (Johnson \& Speare 2003), who reported differential survival of 2 Australian isolates of $B d$, although this study suffered from lack of statistical replication. Subsequently, 2 additional studies tested for differences in virulence between isolates by inoculating frogs with different $B d$ isolates (Berger et al. 2005, using Litoria, and Retallick \& Miera 2007, using Pseudacris triseriata). Both studies found that mean time to frog mortality varied by isolate. Together, these studies provide tantalizing evidence that isolates of $B d$ differ in their virulence; however, these studies did not address whether differences were due to underlying genetic variation between isolates or attenuation of $B d$ in culture.

In addition to reported differences in virulence, $B d$ strains differ morphologically. For example, in a recent study, Fisher et al. (2009a) measured several morphological characters for 9 European isolates. The morphology of 5 isolates of $B d$ from Mallorca, all with the same genotype, differed significantly from isolates recovered from animals in mainland Spain and the UK. Sporangia of all the Mallorcan isolates were significantly smaller when compared with other $B d$ isolates. Additionally, Fisher et al. (2009a) measured the viru- lence of a Mallorcan isolate of $B d$ (TF5a1) and a UK isolate of $B d$ (UKTvB) in the common toad Bufo bufo and in Alytes muletensis. On average, the Mallorcan strain of $B d$ manifested less than $50 \%$ of the virulence observed in the UK strain of the pathogen.

The observation of differences in morphology and virulence among $B d$ strains raises 2 questions. First, if $B d$ has undergone rapid global dispersal, as is suggested by the NPH, then how has such functional and phenotypic diversity been generated in a relatively short period of time? Second, are these data telling us something about the mode and tempo of $B d$ evolution? One approach to addressing these questions is to ask whether rapid rates of change in lineages could be explained by adaptive divergence via natural selection. Specifically, neutral expectations (measured by the between-population variation in neutral marker loci, Wright 1951) can be compared with estimates of between-population variation in quantitative traits (Spitze 1993, McKay \& Latta 2002). This logic was used by Fisher et al. (2009a) to show that a morphological character (size of zoosporangia) was diverging faster between isolates than was expected from the amount of divergence observed at the putatively neutral loci. This observation suggests that zoosporangial size may be under directional selection in the 'hypovirulent' Mallorcan isolates. If the observed patterns are due to selection, it may be because of the unique environment of Mallorca; the maximum temperature of frog microhabitats on the infected island populations is $4.7^{\circ} \mathrm{C}$ higher than the measured growth optima of $B d$, and the infected sites are at low altitude $(185 \mathrm{~m})$. This high temperature/low altitude landscape may have subjected $B d$ to a novel selection regime upon introduction to the island. Alternatively, observations could be consistent with a founder effect given the recent introduction to Mallorca (i.e. small zoospores may be a property of the lineage that was introduced to the island without invoking selection). These alternatives require further testing in different ecological settings, for a wider diversity of $B d$ genotypes and for a greater number of morphological/phenotypic characters.

\section{New marker development}

Until now, finding suitable polymorphic loci with which to address questions about population genetics at multiple spatial scales has been an uphill struggle. Population genetics studies of $B d$ have relied on relatively few genetic markers with exceedingly low levels of genetic variation. The availability of genome sequences for 2 isolates of $B d$, however, is a watershed for population genetic studies of chytridiomycosis. Polymorphisms within and between the strains will be 
easily identifiable from the shotgun sequences. These data will allow the facile discovery of SNPs across the entire genomic landscape. Sampling of hundreds, if not thousands, of SNP loci may be needed to resolve the minor differences among strains. But in the coming years new high-throughput technologies such as highdensity SNP microarrays, chip-based sequence capture methods, and 'next generation' sequencing will provide the data needed to resolve geographic population structure in this pathogen. Besides SNP loci, the complete genome sequences will allow the identification of transposable elements, which have the benefit of being rapidly mobile and thus useful for fingerprinting analysis (e.g. Goodwin et al. 2001).

Although the genomic sequence data will provide a wealth of important data for population genetics and population genomics, several cautions should be raised. First, relying solely on genotyping particular SNPs identified between JAM81 and JEL423 for future studies of additional strains will introduce a problem of 'ascertainment bias' and 'branch collapse' because only a subset of variable sites will be sampled. Instead, future studies should use the 2 available genomes to identify regions that appear to exhibit appropriate levels of variation. These genomic regions can be sequenced in their entirety in an appropriate 'ascertainment panel' to ensure that variable sites are discovered for the specific geographic scale of inquiry (Rosenblum \& Novembre 2007). Second, the addition of hundreds or thousands of loci to future studies does not negate the paramount need to acquire many more samples of $B d$ and closely related chytrid species for use in population genetic studies. Currently the global pool of isolates is small, resulting in low and patchy spatial coverage. Additional effort needs to be mounted to sample larger numbers of isolates of $B d$ from across all scales.

\section{MECHANISMS OF Bd PATHOGENICITY}

Identifying mechanisms of pathogenicity and virulence is a critical goal for molecular studies of $B d$. Molecular techniques such as microarrays (Hwang et al. 2003, Nunes et al. 2005, McDonagh et al. 2008), differential display (Venancio et al. 2002), suppressionsubtractive hybridization (Delgado et al. 2004) and in vivo expression technology (Retallack et al. 2000) have identified candidate genes for pathogenicity in other fungal pathogens. In a subset of these systems virulence factors have been unambiguously confirmed with gene disruption (Brandhorst et al. 1999) and RNA interference (Rappleye et al. 2004). $B d$ is not a genetic model system, in that we do not currently have tools for genetic transformation to create gene knock-outs or knock-downs via RNA interference (RNAi). Development of a transformation system to test gene function using gene disruption or knock-down will probably be hindered by $B d$ 's diploidy, the absence of a completely defined growth medium and the translational issues in dealing with a basal fungal species. However, the potential sensitivity of $B d$ to drugs such as chloramphenicol suggests that the development of a positive selection regime may be possible. Nonetheless, even without the ability to generate knock-outs, we can use powerful comparative and functional genomics tools to identify candidate pathogenicity factors.

\section{Comparative approaches}

A diverse range of fungal pathogens from different regions of the fungal tree (e.g. from basal chytrids to highly derived ascomycetes) attack different hosts (e.g. from plants to humans). Therefore, we do not necessarily expect to find common genetic underpinnings to pathogenicity in all fungal pathogens. Comparative genomics approaches to study $B d$ pathogenicity, however, are likely to be fruitful in several ways.

First, we can compare the $B d$ genome to those of non-pathogenic fungi to identify genetic differences that could be associated with pathogenicity in $B d$. For example, by comparing the $B d$ genome to whole genomes of all other fully sequenced fungi, several gene family 'expansions' have been identified in $B d$ (J. E. Stajich unpubl. data). In these expansions, genes found with one or few copies in other fungi have many copies in $B d$. For example, expansions have been detected in fungalysin metallopeptidase and serine protease families (Rosenblum et al. 2008), 2 protein families that have been implicated in pathogenesis in fungi that infect animal hosts (e.g. Huang et al. 2004, $\mathrm{Xu}$ et al. 2006). Each of these families contains more than 25 members in $B d$, raising the possibility that these gene expansions are associated with $B d$ 's ability to degrade animal skin proteins.

Second, we can compare the $B d$ genome with those of other pathogenic fungi to find evidence for common mechanisms of pathogenicity. Comparisons between $B d$ and other fungal pathogens that 'make their living' in a similar way are likely to be highly fruitful. For example, the 'dermatophytes' are fungal pathogens that cause cutaneous infections in vertebrates. Comparison of $B d$ and other dermatophyte genomes, such as those for the Onygenales fungi Coccidioides (valley fever) and Trichophyton (foot fungus) and the dandruff-causing Basidiomycete yeast Malassezia, will be important in order to establish commonalities of disease-causing mechanisms that evolved in similar niches. In particular, it will be important to study the 
evolution of enzymes that degrade animal proteins like keratin and other molecules that could relate to nutrient acquisition from an animal host. For example, as mentioned above, $B d$ exhibits a dramatic expansion of a family of fungalysin metallopeptidases. Intriguingly a similar multiplication of fungalysin genes has been observed in the Trichophyton and Microsporum dermatophytes (Jousson et al. 2004).

Comparative approaches have been used with some success to identify virulence factors in other fungal pathogens. For example, the transcriptome of the human respiratory pathogen Paracoccidioides brasiliensis was mined for virulence factors by searching for DNA sequences similar to those of putative virulence genes of other pathogenic fungi (Tavares et al. 2005). This study identified candidate genes in several categories including metabolism, cell wall composition and secreted factors. Similarly, we may be able to leverage studies in other fungal pathogens to identify pathways worthy of further study in $B d$. Studies in the human commensal/pathogenic yeast Candida albicans determined that certain covalently linked cell wall proteins may be involved in pathogenicity (de Groot et al. 2004). Adhesin molecules, which allow pathogens to bind to host cells or extracellular matrix, have been identified for several pathogenic fungi (Brandhorst et al. 1999, Hung et al. 2002, Long et al. 2003, Andreotti et al. 2005) and suggest that analysis of cell surface molecules in $B d$ may be important to better understand initiation of host-pathogen interactions.

Finally, we can compare genomes for multiple $B d$ strains to understand genomic patterns of selection. This strategy has been used with other fungal pathogens. For example, comparing 3 isolates of Paracoccidioides brasiliensis, positive selection of putative virulence factors was demonstrated through analysis of genetic variation (Matute et al. 2008). Similarly positive directional selection was detected on cell wall proline-rich antigen in the human pathogen Coccidioides (Johannesson et al. 2004). Ongoing work in Bd genomics involves sequencing genomes from multiple $B d$ strains that differ in virulence to document patterns of variation at putative virulence genes, look for genomic signatures of selection and elucidate the genetic basis of strain differences.

\section{Functional approaches}

Functional genomics approaches can also be useful for identifying genetic patterns associated with $B d$ virulence and pathogenicity. In addition to using the whole $B d$ genome to study variation at the nucleotide level, we can also employ the $B d$ genome to study variation at the level of gene expression. Understanding differences in gene regulation or gene expression is particularly important in cases where a single $B d$ genome may be 'used' in different ways. For example, Rosenblum et al. (2008) looked at differences in gene expression patterns between life stages in $B d$ (the zoospore stage compared with the sporangial stage). This comparison is biologically relevant because both life stages exhibit unique characteristics that could help elucidate disease process. Although zoospores are host-independent, they do exhibit chemotaxis (Moss et al. 2008) and are important in initiating the disease cycle. Sporangia are of obvious interest because they are embedded in host tissue and generate additional zoospores, thereby contributing to increased pathogen loads and pathogen transmission.

Rosenblum et al. (2008) found that zoospores and sporangia exhibit dramatically different expression profiles with more than half of the genes in the $B d$ genome differing in expression between life stages. They also found that sporangia are transcriptionally and metabolically much more complex than zoospores, consistent with previous experiments that have shown that non- $B d$ zoospores contain many stored transcripts and do little de novo transcription (Johnson \& Lovett 1984). The study also identified specific genes for further study that may be involved in cell adhesion, flagellar development and pathogenicity. One of the most interesting patterns found was the differential expression of fungalysin metallopeptidases, a gene family discussed previously that exhibits an expansion in $B d$ and is thought to play a role in keratin degradation by dermatophytes (Jousson et al. 2004). Nearly all fungalysins in the $B d$ genome have higher levels of expression in the sporangia, which makes sense given that this life stage is actually embedded in keratinized frog skin. A single member of the fungalysin family showed higher expression in zoospores and may provide some clues to the initial stages of $B d$ entry into host cells.

The study of differential expression of $B d$ genes between life stages is a first pass at describing functional genomic patterns in this species, and much work remains to be done to identify $B d$ pathogenicity factors and validate their importance. Ongoing research focuses on identifying additional genes associated with $B d$ pathogenicity and virulence and understanding whether patterns at these genes are functionally important. For example, documenting differential expression of $B d$ genes under different growth conditions will demonstrate whether some proteases are upregulated when $B d$ is grown on keratinized amphibian skin (E. B. Rosenblum unpubl. data).

Another application of functional tools is in the quest to understand genetic differences among $B d$ strains. Here we are interested not in using neutral genetic 
variation to describe historical patterns of $B d$ spread but in understanding what genes and proteins differ between strains that vary in morphology or virulence. Discovering candidate genes that are associated with particular phenotypes is particularly challenging; however, genome-scale approaches provide a powerful first step. Using a proteomics approach, Fisher et al. (2009a) found protein-level differences among global $B d$ strains. In this study, isolates of $B d$ from Europe, North America and Australia were genotyped by sequencing 5 polymorphic loci; then the proteomic profiles of these isolates were determined from cultured preparations. Comparing the genetic distance between these $B d$ isolates against the differences in their proteome showed that, as isolates became more genetically dissimilar, they became significantly more different in their protein-expression profiles. Similarly, patterns of variation at the level of the transcriptome vary among strains isolated from different hosts (E. B. Rosenblum unpubl. data). These results suggest that genomic and proteomic fingerprinting methods will be useful for understanding the genetic underpinnings of variation among $B d$ strains. The next step will be to use these methods in well-designed association studies that endeavor to link genetic patterns to strain virulence as assessed in tightly controlled and replicated laboratory experiments.

\section{FROG-Bd INTERACTIONS}

Thus far, we have discussed ways to understand chytridiomycosis through study of the $B d$ genome. The magnitude of $B d$ 's effect on frog populations, however, suggests that we may learn as much about chytridiomycosis from genetic studies of host populations. Integrating genetic research from both the host and pathogen perspectives promises a more comprehensive understanding of how $B d$ is killing frogs and what the population level effects of disease introduction are.

\section{Host population genetics}

Understanding population, metapopulation and phylogeographic patterns in frog species affected by $B d$ is critical for several reasons. First, documenting patterns of frog population structure can provide an important backdrop for understanding patterns of $B d$ spatial distribution. For instance, studies of population structure and species delineations of Rana muscosa and R. sierrae in the Sierra Nevada Mountains of California enabled Morgan et al. (2007) to better interpret patterns of genetic variation observed in $B d$ and led to their conclusion that distribution patterns of $B d$ were best explained by human-assisted movement. This approach, analyzing genetic data from selectively 'neutral' markers, has also been used with success in other host-pathogen systems. For example, the phylogeography of the deer mouse Peromyscus maniculatus was investigated to understand geographic variability of the hantaviruses infecting this species, and to predict where new viral strains may emerge (Dragoo et al. 2006).

Second, 'neutral' markers can also be used to evaluate patterns of frog migration and population connectivity. For example, microsatellite markers have been used in frogs to analyze dispersal patterns (Palo et al. 2004). Understanding the direction and magnitude of frog migration and dispersal events will help resolve how far frogs are transporting $B d$ in different systems. These data can also help predict the likely direction and rate of spread in systems that exhibit wave-like $B d$ invasions (Lips et al. 2008).

Third, population genetic data from frog hosts can be used to test for demographic changes over time caused by chytridiomycosis. For example, tests for population bottlenecks can detect genetic signatures of population reductions in species affected by $B d$ (e.g. reduced genetic diversity, reduced estimates of effective population size). Similarly, reduction of genetic diversity can be correlated with disease-related mortality risk, as shown for Italian agile frogs Rana latastei and Ranavirus (Pearman \& Garner 2005). In systems where samples are available from both before and after $B d$ introduction robust genetic analyses can recognize decline (and potential recovery) of frog populations. The power of this approach merits long-term planning; priority should be placed on collecting pre-infection samples in systems that are currently free of $B d$ but are likely to be invaded in the coming years. One such area of high concern is the island of Madagascar where, despite the occurrence of one of the richest amphibian biodiversity hotspots in the world, $B d$ appears to be absent. The island appears to be, almost uniquely, in a pre-decline phase and is receiving much attention as a priority region with an annual amphibian action plan implementing, amongst other mitigation strategies, quarantine measures (Andreone et al. 2008, Lotters et al. 2009). Such baseline data are likely to prove invaluable in the future when assessing the global trajectory of $B d$-infected species and populations.

\section{Host-pathogen coevolution}

To date, genetic evidence for host-pathogen coevolution in Bd and associated hosts is lacking. For example, studies on disease progression in heavily infected 
areas such as eastern Australia show that host traits, such as breeding habitat and production of antimicrobial peptides, are better predictors of susceptibility than host taxonomy (Woodhams et al. 2006, Kriger \& Hero 2007b). However, the possibility of hostpathogen coevolution merits further investigation because predicting host susceptibility is essential for preventing future species extinctions.

In general, several lines of evidence can indicate coevolution between pathogens and their hosts (Woolhouse et al. 2002, Gomulkiewicz et al. 2007). First, a correlation in the spatial patterns of traits affecting host resistance and pathogen success can point to coevolutionary dynamics. Some evidence suggests that $B d$ strains vary in virulence, and diverse frog species clearly vary in their susceptibility to this pathogen. However, an interaction between host fitness and pathogen fitness has not been demonstrated. That is, we do not know whether virulence of a given $B d$ genotype depends on host genotype. Second, positive selection or the maintenance of polymorphisms in genes involved in host-parasite interactions may also indicate coevolution. Third, comparison of $B d$ and host phylogenies can reveal coevolution. Concordance between trees can reveal cospeciation and potentially coevolution, while discordance can signify biologically important host-switching events, as observed for Ranavirus and tiger salamanders (Storfer et al. 2007). Phylogenetic concordance may be unlikely between $B d$ and its hosts, especially across broad taxonomic groups or geographic regions, because $B d$ infects so many hosts and the evidence is that it has spread far beyond its historic range. However, looking for phylogenetic concordance may be useful in determining where $B d$ has been ancestrally endemic and on which hosts. Goka et al. (2009) observed some evidence of $B d$-host coevolution through the detection of a geographically broad but species-specific clade of $B d$ genotypes from the Japanese giant salamander. One mechanism that could explain such a pattern is direct amphibian to amphibian transmission, perhaps during mating. Further investigation of these patterns may also be useful in explaining or predicting disparity in $B d$ strain virulence on different species or populations of hosts.

\section{Host-pathogen disease genetics}

In addition to studying putatively neutral markers to understand host population genetics, we can analyze variation in frog genes thought to be important for host response to pathogen infection. Variations at frog loci that may be under selection can be analyzed to draw inferences about $B d$ as a selective agent and to deter- mine how species differ in response to infection. For example, Tennessen \& Blouin (2008) investigated patterns of molecular evolution at the brevinin-1 antimicrobial peptide (AMP) locus in 3 species of Rana and found genetic patterns consistent with balancing selection. Although Tennessen \& Blouin (2008) did not associate patterns of allelic diversity with a specific disease agent, similar approaches would be useful in understanding the relationship between frog response to $B d$ and genes encoding specific immune effector molecules. At least in some systems, AMP-profiles help explain frog species susceptibility to $B d$ (Woodhams et al. 2006), suggesting that innate immunity is a key determinant of the outcome of exposure to this pathogen. More work is necessary to determine levels of intra- and interspecific variation in AMPs. Similarly, studying patterns of genetic variation at major histocompatibility complex (MHC) genes could provide insight into whether patterns at other immune function genes are associated with frog resistance or susceptibility (Richmond et al. 2009). It would be particularly productive to study the variation in host defense genes in regions with persistent and declining frog populations and species to determine whether genetic variations in host defenses predict the survivors of the initial wave of $B d$ introduction.

Finally, whole genome studies in frogs can suggest genes that may be important for host-pathogen interaction. For example, Rosenblum et al. (2009) used whole genome assays in the model frog species Xenopus tropicalis to better understand the genetic pathways that are perturbed in frogs that have been exposed to $B d$. Those investigators looked at gene expression patterns in multiple tissues at multiple times during infection and found a surprising lack of immune response in the skin, liver, and spleen of infected frogs. In fact, they found decreased expression of many immune function genes in infected frogs compared with uninfected frogs. Whether or not this suggests the potential for evasion or suppression of an immune response by $B d$ requires further study. Rosenblum et al. (2009) also found strong signatures of physiological disruption in frogs with clinical signs of chytridiomycosis. In the skin of dying frogs Rosenblum et al. (2009) observed genetic signals of disruption of keratin production and repair pathways. Further, the liver showed signatures of chronic stress and disruption of several crucial metabolic and cellular processes (e.g. pathways important for cellular detoxification and blood-gas exchange). These data complement immunological and physiological studies of $B d$-infected frogs and can be used to generate hypotheses about the proximate causes of frog mortality. Similar studies in additional frog species are underway to understand the generality of these results. 


\section{CONCLUSIONS}

Genetic and genomic tools hold great promise for answering many of the persistent questions about the biology and evolution of $B d$. We have focused our discussion on ways to leverage $B d$ genomic sequences to better understand: (1) Bd's genetic architecture and basic biology, (2) its origin, spread and global genetic variation, (3) its genetic mechanisms of pathogenicity and (4) the genetic interaction between $B d$ and its amphibian hosts. Continued research in each of these areas will be fruitful for years to come.

Although $B d$ is far from becoming a model species, the 2 complete genomes that are currently available are an important and rare resource for a non-model species. Genomic technology is continually advancing, and the possibilities for genome-scale inquiry for $B d$ will increase dramatically in the next several years. However, genetic and genomic tools in and of themselves will not unlock all of the remaining mysteries of this species. Integrative ventures are the best way forward, and we highlight 2 examples of how to better situate genetic data for $B d$ in a spatial and ecological context. These examples represent just a small fraction of the many possible opportunities for future research and collaboration.

\section{Associating diverse types of data: global genotype mapping}

It is increasingly clear that chytridiomycosis is the result of complex interactions between $B d$, the individual host and environmental modifiers. To address the risk that $B d$ poses to particular species in particular settings and to make conservation recommendations, epidemiological surveillance needs to incorporate $B d$-profiling (Sintchenko et al. 2007). Profiles should include information on genotype, associated phenotypes, virulence factors and other validated markers. These $B d$ profiles can be integrated with knowledge about the spatial distribution of $B d$ genotypes in amphibian populations and can be used to develop effective and integrated disease-management strategies.

At the global scale, we encourage researchers, whenever possible, to contribute to the ' $B d$ Mapping Project', a major push to understand the extent of $B d$ infection. So far, the mapping project has identified $B d$ in 45 out of 78 countries (58\% of those surveyed) and 387 amphibian species (Fisher et al. 2009b), resulting in a rapidly growing database of over 2449 spatial records. These data are being integrated into an online epidemiological mapping tool, www.spatialepidemiology.net/bd-maps, which is a publicly available repository for $B d$ surveillance data (D. Olson \& D. Aanensen unpubl. data). In tandem is a project to associate ' $B d$ profiles' with the surveillance information. Here, targeted genetic markers for a predetermined set of loci will be used to develop a spatial multilocus sequence typing (MLST; Spratt 1999) scheme for Bd. Comparison of novel genotypes with those held in the database may be determined with Java-based applets such as eBURST (available at: eburst.mlst.net/) to uncover linkages between genotypes. Such analyses can identify the spatial extent of related genotypes, and in doing so, can provide necessary information about the patterns of spread of $B d$.

The development of new genetic tools for studying $B d$ will be a major step forward only if researchers collaborate in compiling a diverse library of isolates from around the world. An effort is underway to catalog global $B d$ isolates as a resource for future studies. Researchers can obtain protocols in multiple languages for isolating and archiving $B d$ as well as submit sample information to the repository at: www. bdbank.org/. Following Voyles (2009), we particularly encourage researchers to isolate and cryoarchive $B d$. The database tools discussed above will aid in the integration of genetic, morphological, virulence and spatial data.

Studies conducted at a local scale (whether in the field or the lab) can also benefit from integration of diverse types of data. By documenting disease introduction and progression in concert with genotyping $B d$ strains, a better understanding of spatial patterns of the strains' spread will emerge. Analyzing the risk of $B d$ establishment to a region depends on identifying the pathways through which disease introduction can occur. Pathways of introduction are often cryptic, such as the import of amphibians from infected areas (Fisher \& Garner 2007) and the translocation of water containing viable zoospores or sloughed skin containing living thalli. $B d$-genotyping is probably the best approach for identifying 'source' and 'sink' dynamics in the global spread of this pathogen. Documenting the timing of new introductions, assessing rates of $B d$ spread, and identifying its vectors are all crucial to determining where control measures can be used to stem the further advance of this species.

\section{Getting out of the lab: ecological genomics}

Frog- $B d$ interactions occur in important biotic and abiotic contexts. For example, abiotic factors such as temperature (e.g. Pounds et al. 2006, Kriger \& Hero 2007a, Lips et al. 2008, Woodhams et al. 2008), elevation (Brem \& Lips 2008), and environmental contaminants (Parris \& Baud 2004, Davidson et al. 2007, Rohr et al. 2008) all mediate host-pathogen interactions. 
Similarly, biotic interactions, such as competition and predation, may affect the outcome of $B d$ exposure or may themselves be influenced by $B d$ infection (Parris \& Beaudoin 2004, Parris \& Cornelius 2004). Other vertebrate members of a community assemblage can also serve as potential $B d$ vectors or reservoirs (Daszak et al. 2004, Beard \& O'Neill 2005). Equally important, however, are microbial interactions. $B d$ is certainly not the only microbial pathogen associated with amphibians. Ranaviruses cause disease in many amphibian species and have been documented concurrently with $B d$ on several species of zoo-reared frogs (Miller et al. 2008) and in the amphibian trade (Schloegel et al. 2009). Opportunistic microbes such as the bacterium Aeromonas hydrophila and the zygomycete fungus Basidiobolus ranarum are often found associated with the skin or gut of amphibians and may exacerbate chytridiomycosis (Rollins-Smith et al. 2002, Green \& Converse 2005, Miller et al. 2008). On the other hand, some microbes may actually confer some resistance to $B d$. Recent work on 'beneficial bacteria' demonstrates that certain bacteria produce compounds that actually inhibit $B d$ growth, possibly providing a first barrier to infection (Harris et al. 2006, Woodhams et al. 2007, Brucker et al. 2008). The possibility that key bacterial species (or entire microbial community assemblages) can have such a dramatic effect on this pathogen's ability to colonize frog skin underscores the importance of studying $B d$ infection in context.

Genetic and genomic approaches alone will not be sufficient to understand $B d$-related amphibian declines, particularly if they are used in isolation. It is essential to apply genetic approaches to natural systems and endeavor to understand the frog- $B d$ interaction in the synergistic abiotic and biotic context in which it occurs. Collaborative efforts integrating ecological and genomic tools, therefore, hold the greatest promise for understanding disease-related amphibian declines.

Acknowledgements. We thank the following funding sources: National Science Foundation (EF-0723563 and IOS-0825355) to E.B.R., National Institutes of Health (P20 RR016448) from the COBRE Program of the National Center for Research Resources to E.B.R., the UK Natural Environmental Research Council to M.C.F. and the Miller Institute for Basic Research in Science to J.E.S. We also thank several anonymous reviewers for comments on the manuscript.

\section{LITERATURE CITED}

Andreone F, Carpenter AI, Cox N, du Preez L and others (2008) The challenge of conserving amphibian megadiversity in Madagascar. PLoS Biol 6:e118

Andreotti PF, da Silva JLM, Bailao AMB, Soares CMA, Benard G, Soares CP, Mendes-Giannini MJS (2005) Isola- tion and partial characterization of a $30 \mathrm{kDa}$ adhesin from Paracoccidioides brasiliensis. Microbes Infect 7:875-881

Annis SL, Dastoor FP, Ziel H, Daszak P, Longcore J (2004) A DNA-based assay identified Batrachochytrium dendrobatidis in amphibians. J Wildl Dis 40:420-428

Beard KH, O'Neill EM (2005) Infection of an invasive frog Eleutherodactylus coqui by the chytrid fungus Batrachochytrium dendrobatidis in Hawaii. Biol Conserv 126:591-595

Bell BD, Carver S, Mitchell NJ, Pledger S (2004) The recent decline of a New Zealand endemic: How and why did populations of Archey's frog Leiopelma archeyi crash over 1996-2001? Biol Conserv 120:189-199

> Berger L, Marantelli G, Skerratt LL, Speare R (2005) Virulence of the amphibian chytrid fungus Batrachochytrium dendrobatidis varies with the strain. Dis Aquat Org 68: 47-50

Bovero S, Sotgiu G, Angelini C, Doglio S, Gazzaniga E, Cunningham AA, Garner TWJ (2008) Detection of chytridiomycosis caused by Batrachochytrium dendrobatidis in the endangered sardinian newt (Euproctus platycephalus) in Southern Sardinia, Italy. J Wildl Dis 44:712-715

> Boyle DG, Boyle DB, Olsen V, Morgan JAT, Hyatt AD (2004) Rapid quantitative detection of chytridiomycosis (Batrachochytrium dendrobatidis) in amphibian samples using real-time Taqman PCR assay. Dis Aquat Org 60:141-148

> Brandhorst TT, Wuthrich M, Warner T, Klein B (1999) Targeted gene disruption reveals an adhesin indispensable for pathogenicity of Blastomyces dermatitidis. J Exp Med 189:1207-1216

Brem FMR, Lips KR (2008) Batrachochytrium dendrobatidis infection patterns among Panamanian amphibian species, habitats and elevations during epizootic and enzootic. Dis Aquat Org 81:189-202

Brucker RM, Baylor CM, Walters RL, Lauer A, Harris RN, Minbiole KPC (2008) The identification of 2,4-diacetylphloroglucinol as an antifungal metabolite produced by cutaneous bacteria of the salamander Plethodon cinereus. J Chem Ecol 34:39-43

Cunningham AA, Garner TWJ, Aguilar-Sanchez V, Banks B and others (2005) Emergence of amphibian chytridiomycosis in Britain. Vet Rec 157:386-387

Curran BPG, Bugeja V (2005) Fungal genetics: a post genomic perspective. In: Kavanagh K (ed) Fungi: biology and applications. Wiley, Chichester

Dastoor FP, Annis SL, Daszak P, Longcore JE, Jones MS, Muths E (2001) PCR-assay to detect Batrachochytrium on amphibians and in the environment. Phytopathology 91:S108 (Abstract)

Daszak P, Strieby A, Cunningham AA, Longcore JE, Brown CC, Porter D (2004) Experimental evidence that the bullfrog (Rana catesbeiana) is a potential carrier of chytridiomycosis, an emerging fungal disease of amphibians. Herpetol J 14:201-207

> Davidson C, Benard MF, Shaffer HB, Parker JM, O'Leary C, Conlon JM, Rollins-Smith LA (2007) Effects of chytrid and carbaryl exposure on survival, growth and skin peptide defenses in foothill yellow-legged frogs. Environ Sci Technol 41:1771-1776

> de Groot PWJ, de Boer AD, Cunningham J, Dekker HL and others (2004) Proteomic analysis of Candida albicans cell walls reveals covalently bound carbohydrate-active enzymes and adhesins. Eukaryot Cell 3:955-965

Delgado N, Hung CY, Tarcha E, Gardner MJ, Cole GT (2004) Profiling gene expression in Coccidioides posadasii. Med Mycol 42:59-71

Di Rosa I, Simoncelli F, Fagotti A, Pascolini R (2007) Ecology: 
the proximate cause of frog declines? Nature 447:E4-E5

Doggett MS, Porter D (1996) Sexual reproduction in the fungal parasite, Zygorhizidium planktonicum. Mycologia 88: 720-732

> Dragoo JW, Lackey JA, Moore KE, Lessa EP, Cook JA, Yates TL (2006) Phylogeography of the deer mouse (Peromyscus maniculatus) provides a predictive framework for research on hantaviruses. J Gen Virol 87:1997-2003

Fisher MC, Garner TW (2007) The relationship between the introduction of Batrachochytrium dendrobatidis, the international trade in amphibians and introduced amphibian species. Fungal Biol Rev 21:2-9

Fisher MC, Bosch J, Yin Z, Stead DA and others (2009a) Proteomic and phenotypic profiling of the amphibian pathogen Batrachochytrium dendrobatidis shows that genotype is linked to virulence. Mol Ecol 18:415-429

Fisher MC, Garner TWJ, Walker SF (2009b) The global emergence of Batrachochytrium dendrobatidis and amphibian chytridiomycosis in space, time and host. Annu Rev Microbiol 63:291-310

- Garcia G, Cunningham AA, Horton DL, Garner TWJ and others (2007) Mountain chickens Leptodactylus fallax and sympatric amphibians appear to be disease free on Montserrat. Oryx 41:398-401

> Goka K, Yokoyama J, Une Y, Kuroki T and others (2009) Amphibian chytridiomycosis in Japan: distribution, haplotypes and possible route of entry into Japan. Mol Ecol 18: 4757-4774

Gomulkiewicz R, Drown DM, Dybdahl MF, Godsoe W and others (2007) Dos and don'ts of testing the geographic mosaic theory of coevolution. Heredity 98:249-258

> Goodwin SB, Cohen BA, Fry WE (1994) Panglobal distribution of a single clonal lineage of the Irish potato famine fungus. Proc Natl Acad Sci USA 91:11591-11595

Goodwin SB, Cavaletto JR, Waalwijk C, Kema GHJ (2001) DNA fingerprint probe from Mycosphaerella graminicola identifies an active transposable element. Phytopathology 91:1181-1188

Green D, Converse KA (2005) Diseases of frogs and toads. In: Majumdar SK, Huffman JE, Brenner FJ, Panah AI (eds) Wildlife diseases: landscape epidemiology, spatial distribution and utilization of remote sensing technology. The Pennsylvania Academy of Science, Easton, PA, p 89-117

> Harris RN, James TY, Lauer A, Simon MA, Patel A (2006) Amphibian pathogen Batrachochytrium dendrobatidis is inhibited by the cutaneous bacteria of amphibian species. EcoHealth 3:53-56

Huang X, Zhao N, Zhang K (2004) Extracellular enzymes serving as virulence factors in nematophagous fungi involved in infection of the host. Res Microbiol 155: 811-816

> Hung CY, Yu JJ, Seshan KR, Reichard U, Cole GT (2002) A parasitic phase-specific adhesin of Coccidioides immitis contributes to the virulence of this respiratory fungal pathogen. Infect Immun 70:3443-3456

> Hwang L, Hocking-Murray D, Bahrami AK, Andersson M, Rine J, Sil A (2003) Identifying phase-specific genes in the fungal pathogen Histoplasma capsulatum using a genomic shotgun microarray. Mol Biol Cell 14:2314-2326

Idnurm A, Walton FJ, Floyd A, Heitman J (2008) Identification of the sex genes in an early diverged fungus. Nature 451: 193-196

> James TY, Porter D, Leander CA, Vilgalys R, Longcore JE (2000) Molecular phylogenetics of the Chytridiomycota supports the utility of ultrastructural data in chytrid systematics. Can J Bot 78:336-350
James TY, Letcher PM, Longcore JE, Mozley-Standridge SE and others (2006) A molecular phylogeny of the flagellated fungi (Chytridiomycota) and description of a new phylum (Blastocladiomycota). Mycologia 98:860-871

James TY, Litvintseva AP, Vilgalys R, Morgan JAT and others (2009) Rapid expansion of an emerging fungal disease into declining and healthy amphibian populations. PLoS Pathog 5:e1000458

Jenkins PT, Genovese K, Ruffler H (2007) Broken screens: the regulation of live animal imports in the United States. Defenders of Wildlife, Washington, DC

Johannesson H, Vidal P, Guarro J, Herr RA, Cole GT, Taylor JW (2004) Positive directional selection in the proline-rich antigen (PRA) gene among the human pathogenic fungi Coccidioides immitis, C. posadasii and their closest relatives. Mol Biol Evol 21:1134-1145

Johnson SA, Lovett JS (1984) Gene expression during development of Blastocladiella emersonii. Exp Mycol 8:132-145

Johnson ML, Speare R (2003) Survival of Batrachochytrium dendrobatidis in water: quarantine and disease control implications. Emerg Infect Dis 9:922-925

Jousson O, Lechenne B, Bontems O, Capoccia S and others (2004) Multiplication of an ancestral gene encoding secreted fungalysin preceded species differentiation in the dermatophytes Trichophyton and Microsporum. Microbiology 150:301-310

Kriger KM, Hero JM (2007a) Large-scale seasonal variation in the prevalence and severity of chytridiomycosis. J Zool 271:352-359

> Kriger KM, Hero JM (2007b) The chytrid fungus Batrachochytrium dendrobatidis is non-randomly distributed across amphibian breeding habitats. Divers Distrib 13: 781-788

> Letcher PM, Powell MJ, Churchill PF, Chambers JG (2006) Ultrastructural and molecular phylogenetic delineation of a new order, the Rhizophydiales (Chytridiomycota). Mycol Res 110:898-915

> Lips KR, Diffendorfer J, Mendelson JR, Sears MW (2008) Riding the wave: reconciling the roles of disease and climate change in amphibian declines. PLoS Biol 6:e72

> Liu YJJ, Hodson MC, Hall BD (2006) Loss of the flagellum happened only once in the fungal lineage: phylogenetic structure of Kingdom Fungi inferred from RNA polymerase II subunit genes. BMC Evol Biol 6:74

> Long KH, Gomez FJ, Morris RE, Newman SL (2003) Identification of heat shock protein 60 as the ligand on Histoplasma capsulatum that mediates binding to CD18 receptors on human macrophages. J Immunol 170:487-494

Longcore JE, Pessier AP, Nichols DK (1999) Batrachochytrium dendrobatidis gen. et sp. nov., a chytrid pathogenic to amphibians. Mycologia 91:219-227

Lotters S, Rodder D, Bielby J, Bosch J and others (2009) Meeting the challenge of conserving Madagascar's megadiverse amphibians: addition of a risk-assessment for the chytrid fungus (comment to Andreone et al. 2008, PLoS Biol 6:e118). PLoS Biol 6, 7 May 2009

Mandegar MA, Otto SP (2007) Mitotic recombination counteracts the benefits of genetic segregation. Proc Biol Sci 274:1301-1307

Martin F, Selosse MA (2008) The Laccaria genome: a symbiont blueprint decoded. New Phytol 180:296-310

> Matute DR, Quesada-Ocampo LM, Rauscher JT, McEwen JG (2008) Evidence for positive selection in putative virulence factors within the Paracoccidioides brasiliensis species complex. PLoS Neglected Trop Dis 2:e296

$>$ McDonagh A, Fedorova ND, Crabtree J, Yu Y and others (2008) Sub-telomere directed gene expression during ini- 
tiation of invasive aspergillosis. PLoS Pathog 4:e1000154 McKay JK, Latta RG (2002) Adaptive population divergence: markers, QTL and traits. Trends Ecol Evol 17:285-291

Miller DL, Rajeev S, Brookins M, Cook J, Whittington L, Baldwin CA (2008) Concurrent infection with Ranavirus, Batrachochytrium dendrobatidis, and Aeromonas in a captive anuran colony. J Zoo Wildl Med 39:445-449

- Morehouse EA, James TY, Ganley ARD, Vilgalys R, Berger L, Murphy PJ, Longcore JE (2003) Multilocus sequence typing suggests the chytrid pathogen of amphibians is a recently emerged clone. Mol Ecol 12:395-403

- Morgan JAT, Vredenburg VT, Rachowicz LJ, Knapp RA and others (2007) Population genetics of the frog-killing fungus Batrachochytrium dendrobatidis. Proc Natl Acad Sci USA 104:13845-13850

> Mortimer RK (2000) Evolution and variation of the yeast (SaCcharomyces) genome. Genome Res 10:403-409

Moss AS, Reddy NS, Dorta JIM, Francisco MJS (2008) Chemotaxis of the amphibian pathogen Batrachochytrium dendrobatidis and its response to a variety of attractants. Mycologia 100:1-5

> Noble SM, Johnson AD (2007) Genetics of Candida albicans, a diploid human fungal pathogen. Annu Rev Genet 41: 193-211

> Nunes LR, de Oliveira RC, Leite DB, da Silva VS and others (2005) Transcriptome analysis of Paracoccidioides brasiliensis cells undergoing mycelium-to-yeast transition. Eukaryot Cell 4:2115-2128

Palo JU, Lesbarreres D, Schmeller DS, Primmer CR, Merila J (2004) Microsatellite marker data suggest sex-biased dispersal in the common frog Rana temporaria. Mol Ecol 13: 2865-2869

Parker JDK, Bradley BA, Mooers AO, Quarmby LM (2007) Phylogenetic analysis of the neks reveals early diversification of ciliary-cell cycle kinases. PLoS ONE 2:e1076

Parris MJ, Baud DR (2004) Interactive effects of a heavy metal and chytridiomycosis on gray treefrog larvae (Hyla chrysoscelis). Copeia 2004:344-350

> Parris MJ, Beaudoin JG (2004) Chytridiomycosis impacts predator-prey interactions in larval amphibian communities. Oecologia 140:626-632

Parris MJ, Cornelius TO (2004) Fungal pathogen causes competitive and developmental stress in larval amphibian communities. Ecology 85:3385-3395

Pearman PB, Garner TWJ (2005) Susceptibility of Italian agile frog populations to an emerging strain of Ranavirus parallels population genetic diversity. Ecol Lett 8:401-408

> Picco AM, Collins JP (2008) Amphibian commerce as a likely source of pathogen pollution. Conserv Biol 22: 1582-1589

Piotrowski JS, Annis SL, Longcore JE (2004) Physiology of Batrachochytrium dendrobatidis, a chytrid pathogen of amphibians. Mycologia 96:9-15

Pounds JA, Bustamante MR, Coloma LA, Consuegra JA and others (2006) Widespread amphibian extinctions from epidemic disease driven by global warming. Nature 439: 161-167

Rachowicz LJ, Hero JM, Alford RA, Taylor JW and others (2005) The novel and endemic pathogen hypotheses: competing explanations for the origin of emerging infectious diseases of wildlife. Conserv Biol 19:1441-1448

> Rachowicz LJ, Knapp RA, Morgan JAT, Stice MJ, Vredenburg VT, Parker JM, Briggs CJ (2006) Emerging infectious disease as a proximate cause of amphibian mass mortality. Ecology 87:1671-1683

Rappleye CA, Engle JT, Goldman WE (2004) RNA interference in Histoplasma capsulatum demonstrates a role for alpha-(1,3)-glucan in virulence. Mol Microbiol 53: 153-165

> Retallack DM, Deepe GS, Woods JP (2000) Applying in vivo expression technology (IVET) to the fungal pathogen Histoplasma capsulatum. Microb Pathog 28:169-182

Retallick RWR, Miera V (2007) Strain differences in the amphibian chytrid Batrachochytrium dendrobatidis and non-permanent, sub-lethal effects of infection. Dis Aquat Org 75:201-207

Richmond JQ, Savage AE, Rosenblum EB, Zamudio KR (2009) Towards immunogenetic studies of amphibian chytridiomycosis: linking innate and acquired immunity. Bioscience 59:311-320

- Rohr JR, Schotthoefer AM, Raffel TR, Carrick HJ and others (2008) Agrochemicals increase trematode infections in a declining amphibian species. Nature 455:1235-1239

Rollins-Smith LA, Doersam JK, Longcore JE, Taylor SK, Shamblin JC, Carey C, Zasloff MA (2002) Antimicrobial peptide defenses against pathogens associated with global amphibian declines. Dev Comp Immunol 26:63-72

> Rosenblum EB, Novembre J (2007) Ascertainment bias in spatially structured populations: a case study in the eastern fence lizard. J Hered 98:331-336

Rosenblum EB, Stajich JE, Maddox N, Eisen MB (2008) Global gene expression profiles for life stages of the deadly amphibian pathogen Batrachochytrium dendrobatidis. Proc Natl Acad Sci USA 105:17034-17039

Rosenblum EB, Maddox N, Murdoch G, Moralis H, Eisen MB, Robert J, Poorten T (2009) Genome-wide transcritional response of Silurana (Xenopus) tropicalis to infection with the deadly chytrid fungus. PLoS ONE 4:e6494

> Ruiz-Trillo I, Burger G, Holland PWH, King N, Lang BF, Roger AJ, Gray MW (2007) The origins of multicellularity: a multi-taxon genome initiative. Trends Genet 23:113-118

Schloegel LM, Picco AM, Kilpatrick AM, Davies AJ, Hyatt AD, Daszak P (2009) Magnitude of the US trade in amphibians and presence of Batrachochytrium dendrobatidis and ranavirus infection in imported North American bullfrogs (Rana catesbeiana). Biol Conserv 142:1420-1426

Simmons DR, James TY, Meyer A, Longcore JE (2009) Lobulomycetales, a new order in the Chytridiomycota. Mycol Res 113:450-460

Sintchenko V, Iredell JR, Gilbert GL (2007) Pathogen profiling for disease management and surveillance. Nat Rev Microbiol 5:464-470

Spitze K (1993) Population structure in Daphnia obtusa: quantitative genetic and allozymic variation. Genetics 135: 367-374

Spratt BG (1999) Multilocus sequence typing: molecular typing of bacterial pathogens in an era of rapid DNA sequencing and the Internet. Curr Opin Microbiol 2: 312-316

Stajich JE, Dietrich FS, Roy SW (2007) Comparative genomic analysis of fungal genomes reveals intron-rich ancestors. Genome Biol 8:R223

Storfer A, Alfaro ME, Ridenhour BJ, Jancovich JK, Mech SG, Parris MJ, Collins JP (2007) Phylogenetic concordance analysis shows an emerging pathogen is novel and endemic. Ecol Lett 10:1075-1083

Tavares AH, Silva SS, Bernardes VV, Maranhao AQ, Kyaw CM, Pocas-Fonseca M, Silva-Pereira I (2005) Virulence insights from the Paracoccidioides brasiliensis transcriptome. Genet Mol Res 4:372-389

> Taylor JW, Berbee ML (2006) Dating divergences in the fungal tree of life: review and new analyses. Mycologia 98: 838-849

Taylor JW, Jacobson DJ, Fisher MC (1999) The evolution of 
asexual fungi: reproduction, speciation and classification. Annu Rev Phytopathol 37:197-246

Tennessen JA, Blouin MS (2008) Balancing selection at a frog antimicrobial peptide locus: fluctuating immune effector alleles? Mol Biol Evol 25:2669-2680

Ullrich RC, Anderson JB (1978) Sex and diploidy in Armillaria mellea. Exp Mycol 2:119-129

Une Y, Kadekaru S, Tamukai K, Goka K, Kuroki T (2008) First report of spontaneous chytridiomycosis in frogs in Asia. Dis Aquat Org 82:157-160

Venancio EJ, Kyaw CM, Mello CV, Silva SP, Soares CMA, Felipe MSS, Silva-Pereira I (2002) Identification of differentially expressed transcripts in the human pathogenic fungus Paracoccidioides brasiliensis by differential display. Med Mycol 40:45-51

> Voyles J, Cashins SD, Rosenblum EB, Puschendorf R (2009) Preserving pathogens for wildlife conservation: a case for action on amphibian declines. Oryx 43:527-529

Walker SF, Salas MB, Jenkins D, Garner TWJ and others (2007) Environmental detection of Batrachochytrium dendrobatidis in a temperate climate. Dis Aquat Org 77:105-112

Walker SF, Bosch J, James TY, Litvintseva AP and others (2008) Invasive pathogens threaten species recovery programs. Curr Biol 18:R853-R854

Weldon C, du Preez LH, Hyatt AD, Muller R, Speare R (2004) Origin of the amphibian chytrid fungus. Emerg Infect Dis 10:2100-2105

Editorial responsibility: Alex Hyatt, Geelong, Victoria, Australia
Woodhams DC, Rollins-Smith LA, Carey C, Reinert L, Tyler MJ, Alford RA (2006) Population trends associated with skin peptide defenses against chytridiomycosis in Australian frogs. Oecologia 146:531-540

> Woodhams DC, Vredenburg VT, Simon MA, Billheimer D and others (2007) Symbiotic bacteria contribute to innate immune defenses of the threatened mountain yellow-legged frog, Rana muscosa. Biol Conserv 138: 390-398

Woodhams DC, Alford RA, Briggs CJ, Johnson M, RollinsSmith LA (2008) Life-history trade-offs influence disease in changing climates: strategies of an amphibian pathogen. Ecology 89:1627-1639

> Woolhouse MEJ, Webster JP, Domingo E, Charlesworth B, Levin BR (2002) Biological and biomedical implications of the co-evolution of pathogens and their hosts. Nat Genet 32:569-577

Wright S (1951) The genetic structure of populations. Ann Eugen 15:323-354

Wu W, Lockhart SR, Pujol C, Srikantha T, Soll DR (2007) Heterozygosity of genes on the sex chromosome regulates Candida albicans virulence. Mol Microbiol 64:1587-1604

Xu JR, Peng YL, Dickman MB, Sharon A (2006) The dawn of fungal pathogen genomics. Annu Rev Phytopathol 44: 337-366

Zolan ME (1995) Chromosome-length polymorphism in fungi. Microbiol Rev 59:686-698

Submitted: December 8, 2008; Accepted: November 12, 2009 Proofs received from author(s): December 11, 2009 